\title{
Sienogranitos leucocráticos do Domínio Macururé, Sistema Orogênico Sergipano, Nordeste do Brasil: Stock Glória Sul
}

\author{
Leucocratic syenogranites the Macururé Domain, \\ Sergipano Orogenic System, Northeastern Brazil: Glória Sul Stock \\ Joane Almeida da Conceição ${ }^{1 *}$, \\ Maria de Lourdes da Silva Rosa ${ }^{2}$, Herbet Conceição ${ }^{1,2}$
}

RESUMO: O Stock Glória Sul (SGS) $\left(41 \mathrm{~km}^{2}\right)$ é arredondado e intrusivo na parte central do Domínio Macururé, no Sistema Orogênico Sergipano (SOS). Internamente o Stock é formado por vários tipos de sienogranitos leucocráticos (biotita sienogranito, sienogranito com muscovita e biotita e muscovita sienogranito). Os biotita sienogranitos apresentam abundância de enclaves máficos microgranulares que correspondem a sienitos e são ocasionais nos sienogranitos com muscovita e biotita. Os sienogranitos são metaluminosos, com termos mais evoluídos peraluminosos, posicionando-se no campo dos granitos do tipo I e exibem assinatura geoquímica cálcio-alcalino de alto $\mathrm{K}_{2} \mathrm{O}$. Os enclaves sieníticos são metaluminosos e exibem assinatura shoshonítica. Os dados geoquímicos sugerem que as diferentes rochas presentes no SGS podem ser explicadas como produto da mistura entre um magma fortemente diferenciado e peraluminoso $\left(\approx 73 \% \mathrm{SiO}_{2}\right)$ com outro máfico shoshonítico $\left(\approx 56 \% \mathrm{SiO}_{2}\right)$, representado pelos enclaves. Os valores dos elementos traços são mais elevados nos enclaves do que nos granitos, tais como $\mathrm{Ba}(1.179$ - $319 \mathrm{ppm})$, Rb (351 - 55,3 ppm), Y (16,7 $1,6 \mathrm{ppm})$. Os padróes de elementos terras raras mostram variação de $\sum 38,58-299,21 \mathrm{ppm}, \mathrm{La}_{\mathrm{N}} / \mathrm{Yb}_{\mathrm{N}} 12,57-137,22 \mathrm{e} \mathrm{Eu} / \mathrm{Eu}^{*} 0,72-1,94$. O SGS, ante aos resultados obtidos neste estudo, evidencia que a granitogênese no Domínio Macururé (DM) é complexa e que os sienogranitos leucocráticos que ocorrem bem distribuídos nesse domínio são pós-tectônicos e representam o produto de interação entre magmas riolíticos peraluminosos com magmas mantélicos shoshoníticos.

PALAVRAS-CHAVE: Granitos; Geoquímica; Petrologia; Sergipe.
ABSTRACT: The Glória Sul Stock (SGS) $\left(41 \mathrm{~km}^{2}\right)$ is a roundshaped pluton, which intrudes the metasediments of the central area of the Macururé Domain, in the Sergipano Orogenic System (SOS). The stock encompasses a number of leucocratic syenogranites, including biotite syenogranite, muscovite-biotite bearing syenogranite and muscovite syenogranite. Mafic microgranular enclaves with syenitic composition are abundant in the biotite syenogranites but very rare in the muscovite-biotite bearing syenogranites. The syenogranites are predominantly metaluminous although the more evolved rocks show a peraluminous character. They can be classified as I-type and high-K calc-alkaline rocks. The syenitic enclaves are metaluminous and show shoshonitic geochemical characteristics. Geochemical modeling suggests that petrological diversity may be explained by considering mixing between peraluminous magma with ca. $73 \% \mathrm{SiO}_{2}$ and a mafic shoshonitic magma with ca. $56 \% \mathrm{SiO}_{2}$. Trace elements contents $(\mathrm{Ba}=1,179$ 319 ppm; $R b=351-55.3$ ppm; $Y=16.7-1.6$ ppm) are higher in the enclaves than in the granites. REE contents range from $38.58-299.21 \mathrm{ppm} ; \mathrm{La} / Y b_{N}=12.57-137.22$ and $E u / E u^{*}=$ $0.72-1.94$. The present data indicates that granitogenesis in the Macururé Domain (DM) is complex as well as that the widespread leucocratic syenogranites are post-tectonic, having been generated through interaction between peraluminous rhyolitic magmas and mantellic shoshonitic magmas.

KEYWORDS: Granites; Geochemistry; Petrology; Sergipe State.

${ }^{1}$ Curso de Pós-Graduação em Geologia, Universidade Federal da Bahia - UFBA, Salvador (BA), Brasil. E-mail: joanealmeida@yahoo.com.br ²Programa de Pós-Graduação em Geociências e Análise de Bacias, Universidade Federal de Sergipe - UFS, São Cristóvão(SE), Brasil. E-mail: lrosa@ufs.br; herbet@ufs.br *Autor correspondente.

Manuscrito ID: 20150044. Recebido em: 17/11/2015. Aprovado em: 22/02/2016 


\section{INTRODUÇÃO}

A variedade de granitos no Domínio Macururé (DM), no Estado de Sergipe, foi descrita por Humphrey e Allard (1969) ao identificarem a presença de corpos de natureza granítica, granodiorítica, monzonítica e diorítica nesses terrenos, os quais foram reunidos sob a terminologia de granitos do Tipo Glória. Posteriormente, na década de 1970, durante a elaboração de projeto de cartografia geológica básica, responsável pelo primeiro mapa geológico de Sergipe (Silva Filho et al. 1979), a terminologia de granitos Tipo Glória foi mantida para os novos corpos cartografados nesse domínio.

Os granitos do DM voltam a ser objeto de estudos na década de 1980, durante a confecção do mapa geológico da Folha Carira (Santos et al. 1988), quando foram obtidos seus primeiros dados geoquímicos e eles passaram a ser considerados como intrusóes tardias a posteriores a colisão responsável pela estruturaçáo do Sistema Orogênico Sergipano (SOS). Posteriormente, Fujimori (1989) fornece novos dados geoquímicos para granitos nas partes leste e central do Domínio Macururé, e Chaves (1991), para corpos nas partes central e oeste desse mesmo domínio.

Os trabalhos de Long et al. (2005), Silva Filho et al. (1997, 2013), Bueno et al. (2009), Oliveira (2014), Lisboa (2014), Silva (2014) e Oliveira et al. $(2010,2015)$ forneceram volume importante de dados petrográficos e geoquímicos da granitogênese do DM, confirmando a variedade de tipos petrográficos, identificando a dominância da afinidade cálcio-alcalina desse magmatismo e estabelecendo que esse plutonismo perdurou por cerca de $58 \mathrm{Ma}$ (628 a $570 \mathrm{Ma})$.

Estudos recentes, petrológicos e de detalhe, em intrusões graníticas no DM (e.g. Oliveira 2014; Lisboa 2014; Silva 2014; Santos 2014) têm revelado que a maioria desses corpos não é homogênea tanto sob o ponto de vista petrográfico como geoquímico, assim como em suas afinidades geoquímicas, traduzindo uma evolução complexa, envolvendo a coexistência de vários magmas, quando da formação dessas intrusôes. Este trabalho objetivou apresentar e discutir os resultados obtidos do estudo realizado no Stock Glória Sul (SGS), que constitui, devido as suas dimensôes e diversidade faciológica, o corpo mais importante de natureza sienogranítica leucocrática dentre os granitos do Tipo Glória no DM.

\section{GEOLOGIA REGIONAL}

O SOS, também nomeado como Faixa Sergipana ou Faixa de Dobramentos Sergipana, é o resultado da colisão neoproterozoica entre o Maciço Pernambuco-Alagoas, ao norte, e o Cráton do São Francisco, ao sul (Santos et al. 1998), e cujo clímax situa-se entre 590 e $570 \mathrm{Ma}$ (Bueno et al. 2009; Oliveira et al. 2010).

O SOS foi inicialmente interpretado como: geossinclinal (Humphrey e Allard 1969; Silva Filho et al. 1979); resultante de colagem de domínios geológicos (Santos et al. 1988; Davison e Santos 1989); e, posteriormente, como um sistema colisional (D'el-Rey Silva 1999; Oliveira et al. 2006).

A compartimentação dos terrenos do SOS em domínios proposta por Davison e Santos (1989), cujos limites são feitos por zonas de cisalhamentos (Fig. 1), tem sido bem-aceita pelos pesquisadores que estudaram essa região (e.g. Santos et al. 1998; D’el-Rey Silva 1999; Oliveira et al. 2010). As estruturas nesses terrenos evidenciam transporte de massa de nordeste para sudoeste, colocando parte deles sobre o Cráton do São Francisco (Jardim de Sá et al. 1986). De norte para sul os domínios do SOS são nomeados de: Canindé, Poço Redondo, Marancó, Macururé, Vaza-Barris e Estância (Fig. 1). Dois deles, Vaza-Barris e Estância, essencialmente sedimentares, localizados no sudoeste de Sergipe (Fig. 1), não apresentam plutonismo e as condiçôes metamórficas são de muito baixo grau. Os outros domínios contêm diversidade de granitos e as condiçóes metamórficas atingem fácies anfibolito alto.

$\mathrm{O} \mathrm{DM}$, com área de aproximadamente $2.000 \mathrm{~km}^{2}$, constitui uma faixa com largura aproximada $55 \mathrm{~km}$ orientada SW-NE. Grande parte de seus terrenos é formada por metassedimentos (filitos, metarenitos, metagrauvacas, metaritmitos) com intercalaçôes centimétricas de mármores, calciossilicáticas, itabiritos e rochas vulcânicas que foram submetidos localmente a condições da fácies hornblenda hornfels, particularmente nas vizinhanças das intrusóes graníticas. Ele é formado por metassedimentos e interpretado como uma cunha turbidítica mesoproterozoica, com até $13 \mathrm{~km}$ de espessura (D’el-Rey Silva 1999).

O Domínio Marancó é uma sequência metassedimentar pelítica e psamítica, com estratos de andesitos e dacitos cálcio-alcalinos, com intercalaçóes de basaltos, gabros e serpentinitos (Silva Filho et al. 1979; Oliveira et al. 2010) e com metamorfismo alcançando a fácies anfibolito (Santos et al. 1998).

O Domínio Poço Redondo compóe-se de complexa associação de migmatitos com ortognaisses tonalíticos e granodioríticos e contém várias intrusōes graníticas (Santos et al. 1988; Oliveira et al. 2006).

O Domínio Canindé é formado por rochas vulcanossedimentares com intercalaçóes de metapelitos, grauvacas, metachertes, grafita xisto, calciossilicáticas, mármores, cortados por diques máficos e félsicos e gabros (Santos et al. 1998; Oliveira et al. 2006). O Complexo Gabróico Canindé, que 
ocorre igualmente nesse domínio, é composto por olivina gabronoritos maciços e estratificados, leucograbro, anortosito, troctolitos com menor participação de gabros pegmatíticos, noritos e peridotitos.

\section{Granitogênese no Domínio Macururé}

Esse domínio tem cerca de 60 intrusóes de granitos (Fig. 2). A reunião de dados geológicos, petrográficos, geoquímicos e geocronológicos obtidos até o momento (e.g. Humphrey e Allard 1969; Silva Filho et al. 1979; Fujimori 1989; Gaston e Santos 1989; Chaves 1991; D’el-Rey Silva 1995; Silva Filho et al. 1997; Long et al. 2005; Bueno et al. 2009; Oliveira et al. , 2010, 2015; Conceição 2014; Lisboa 2014; Oliveira 2014; Silva 2014; Borges 2015; Melo 2015; Moura Neto 2015) permitiu identificar que existe uma zonalidade na distribuição espacial dos tipos de granitos (Fig. 2). Nesse contexto, têm-se quatro conjuntos de plutonismos:

1. granodiorítico cálcio-alcalino de alto potássio;

2. monzonítico shoshonítico;

3. sienogranítico leucocrático cálcio-alcalino de alto potássio;

4. granítico cálcio-alcalino com textura rapakivi.

O plutonismo granodiorítico cálcio-alcalino de alto potássio é representado por cerca de 6 corpos (Fig. 2), com idades compreendidas entre $618 \pm 4 \mathrm{Ma}$ e $625 \pm 2 \mathrm{Ma}$ (Silva 2014; Long et al. 2005, respectivamente), que se localizam na parte oeste do DM e têm como corpos mais importantes Santa Helena, Coronel João Sá (no Estado da Bahia, Long et al. 2005) e o Stock Lagoa do Roçado (Silva 2014).

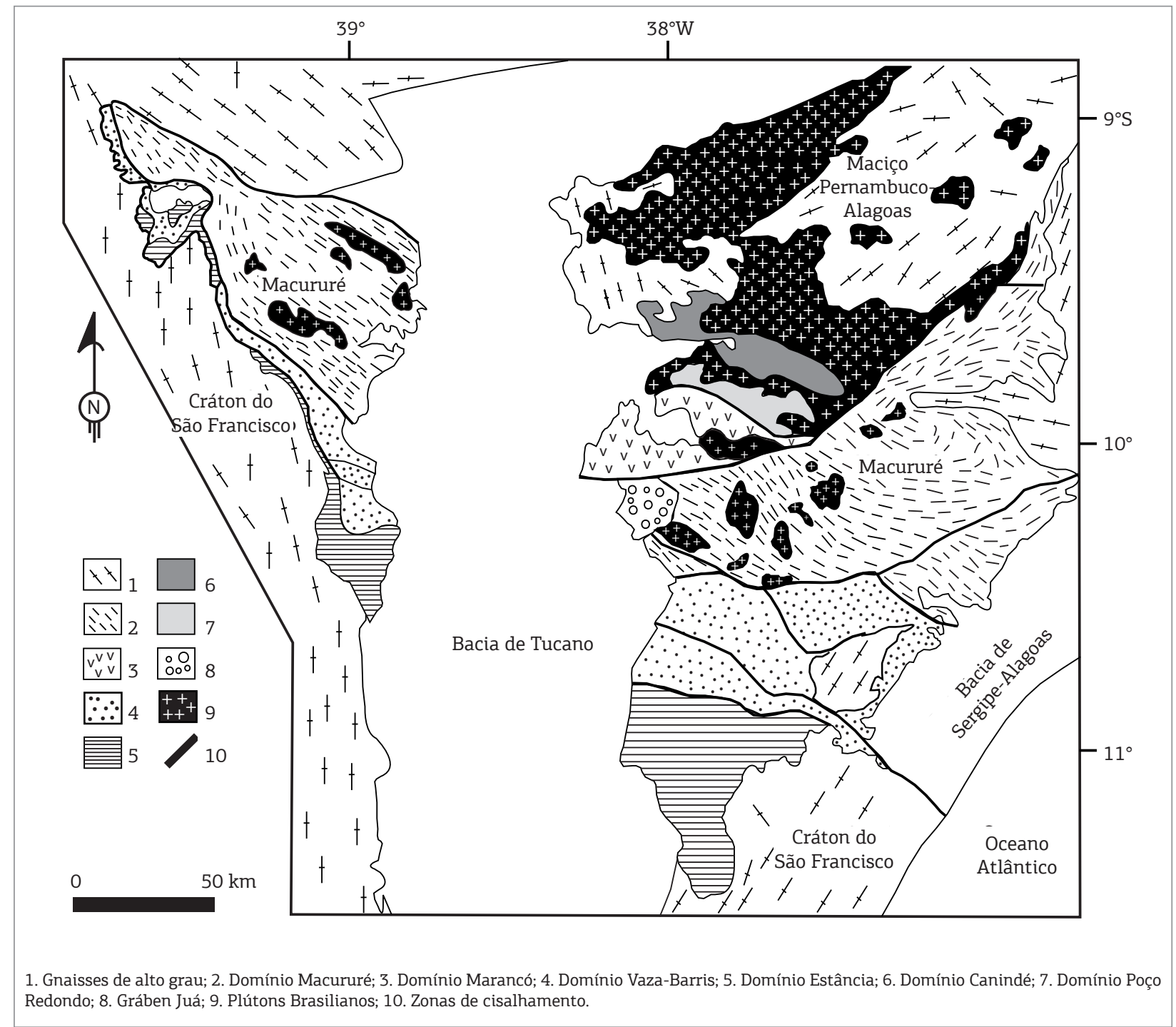

Figura 1. Esquema geológico do Sistema Orogênico Sergipano, mostrando os domínios descritos neste trabalho (Davison e Santos 1989). 
O conjunto monzonítico shoshonítico reune cerca de 11 stocks (Fig. 2) e tem como representante típico o Stock Monzonítico Glória Norte, com idade de $588 \pm$ $5 \mathrm{Ma}$ (Lisboa 2014). Esses Stocks distribuem-se na parte centro-oeste do DM por uma faixa de $14 \mathrm{~km}$ de largura orientada NE-SW. Diferem das outras intrusóes desse domínio por apresentarem riqueza em enclaves com afinidade shoshonítica-ultrapotássica e cumuláticos (flogopita diopsídio cumulato).

O grupo dos sienogranitos leucocráticos é cálcio-alcalino de alto potássio, contendo muscovita e muscovita e biotita, e representa o tipo mais abundante no DM
(Fig. 2). A idade desse magmatismo varia entre $571 \pm 9 \mathrm{Ma}$ e $584 \pm 10 \mathrm{Ma}$ (Bueno et al. 2009). Ele é representado por cerca de duas dezenas de Stocks, e as melhores exposiçôes são os Stocks Glória Sul (objeto deste trabalho), Pedra Furada, Angico e Lagoas.

O plutonismo granítico cálcio-alcalino com textura rapakivi é representado pelos Stocks Propriá, Fazenda Alvorada e Amparo do São Francisco (Santos 2014) e a idade disponível é de $643 \pm 72 \mathrm{Ma}$ (Brito Neves e Cordani 1973). Caracteriza-se tanto pela riqueza quanto pela abundância de enclaves e limita-se a ocorrer unicamente na parte leste do DM.

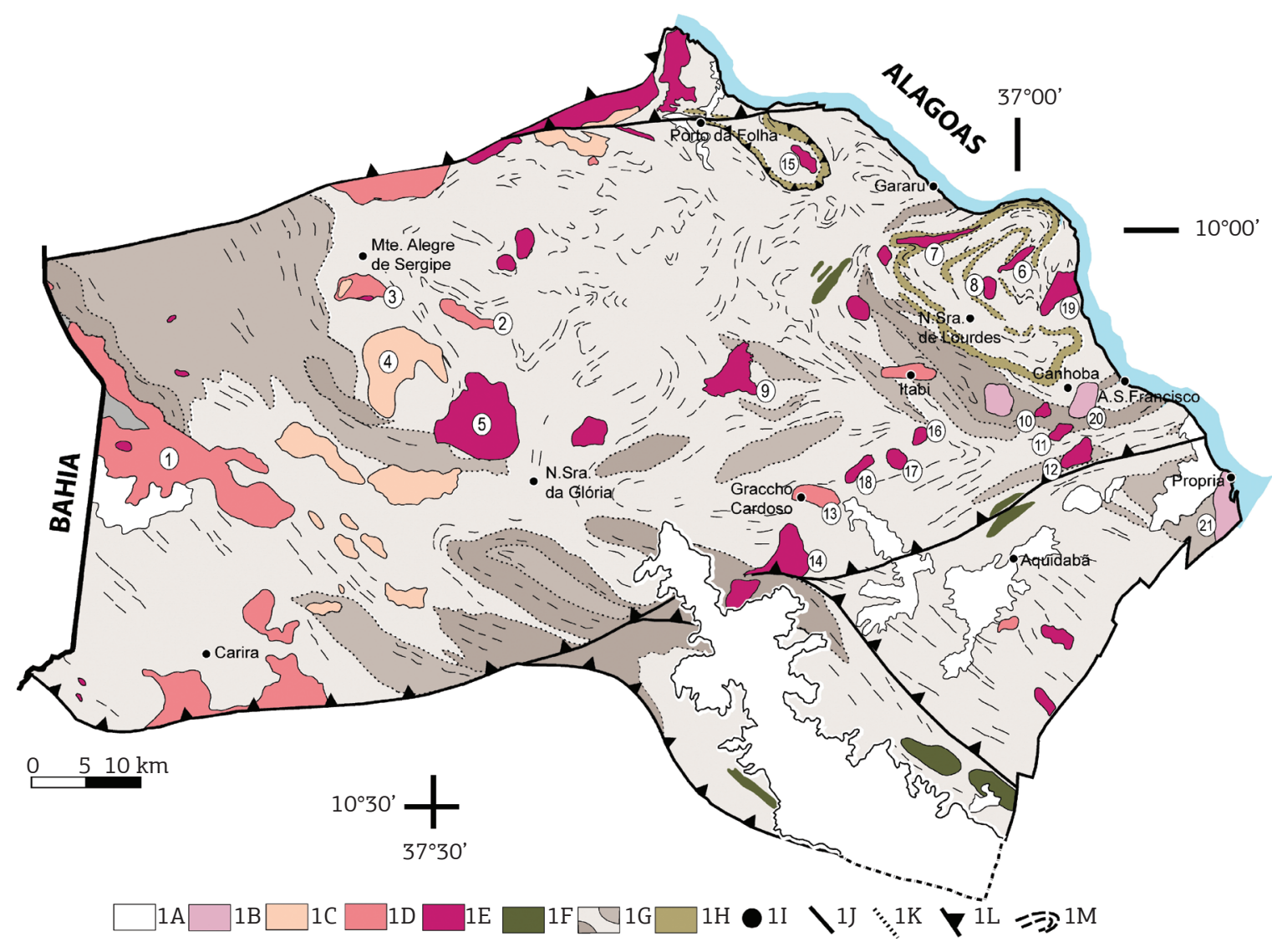

1A: Coberturas terrígenas arenosas e argilosas; 1B: granitos cálcio-alcalino com textura rapakivi; 1C: monzonitos shoshoníticos; 1D: granodioritos cálcio-alcalino de alto potássio; 1E: sienogranitos leucocráticos; 1F: corpos máficos-ultramáficos; 1G: metassedimentos do Domínio Macururé; 1H: quartzitos; 1I: municípios; 1J: contato definido; 1K: contato gradacional; 1L: falha contracional; 1M: lineamentos. Plútons: 1: Santa Helena; 2: Lagoa do Roçado; 3: Monte Alegre de Sergipe; 4: Glória Norte; 5: Glória Sul; 6: Pedra Furada; 7: Angico; 8: Lagoas; 9: Várzea Nova; 10: Canhoba; 11: Gravatá; 12: Lagoa do Mato; 13: Graccho Cardoso; 14: Lagoa de Dentro; 15: Serra das Intãs; 16: Frutuoso; 17: Mocambo 18: Queimadinha; 19: Areias; 20: Amparo do São Francisco; 21: Propriá.

Figura 2. Esquema geológico do Domínio Macururé obtido a partir de Santos et al. (1997) acrescido das informações dos trabalhos de: Fujimori (1989), Chaves (1991), Long et al. (2005), Bueno et al. (2009), Conceição (2014), Silva (2014), Oliveira (2014), Lisboa (2014), Lisboa et al. (2014), Borges (2015), Oliveira et al. (2010, 2015), Melo (2015) e Moura Neto (2015). 


\section{GEOLOGIA LOCAL}

O SGS, com $41 \mathrm{~km}^{2}$, tem forma arredondada, sendo intrusivo em metassedimentos do DM (Fig. 3). O Stock apresenta uma idade $\mathrm{Rb} / \mathrm{Sr}$ de $630 \pm 73 \mathrm{Ma}$ (Brito Neves e Cordani 1973). Esse Stock tem bons afloramentos e vários deles ocorrem em pedreiras, o que facilitou a coleta de amostras e a observaçáo das estruturas. Os contatos com os metassedimentos são bruscos, marcados pela abundância de xenólitos das encaixantes e por diques de granitos $(<2 \mathrm{~m}$ de espessura) que saem do Stock e adentram nas encaixantes. Ocasionalmente, têm-se nos granitos enclaves máficos microgranulares e surmicáceos.
A intrusão do SGS gera metamorfismo de contato nos metassedimentos encaixantes com a formação de hornfels. Esses são facilmente identificados pelo aumento da granulação dos cristais de muscovita, quartzo, granada e biotita, e os níveis calciossilicáticos deixam de ser afaníticos e passam a ter granulação grossa, com cristais de hornblenda, zoisita, oligoclásio, almandina, titanita e calcita (Conceiçáo 2014). Nos metassedimentos a leste em contato com o Stock têm-se forte recristalização e formação de estruturas de mobilidade e abundância em diques de granitos com granada, sugerindo que tenha ocorrido fusão parcial (Fig. 4). Nessas rochas, a presença de oligoclásio-andesina $(28-34 \%$ An) associada a granada, ortoclásio, muscovita, biotita e minerais opacos

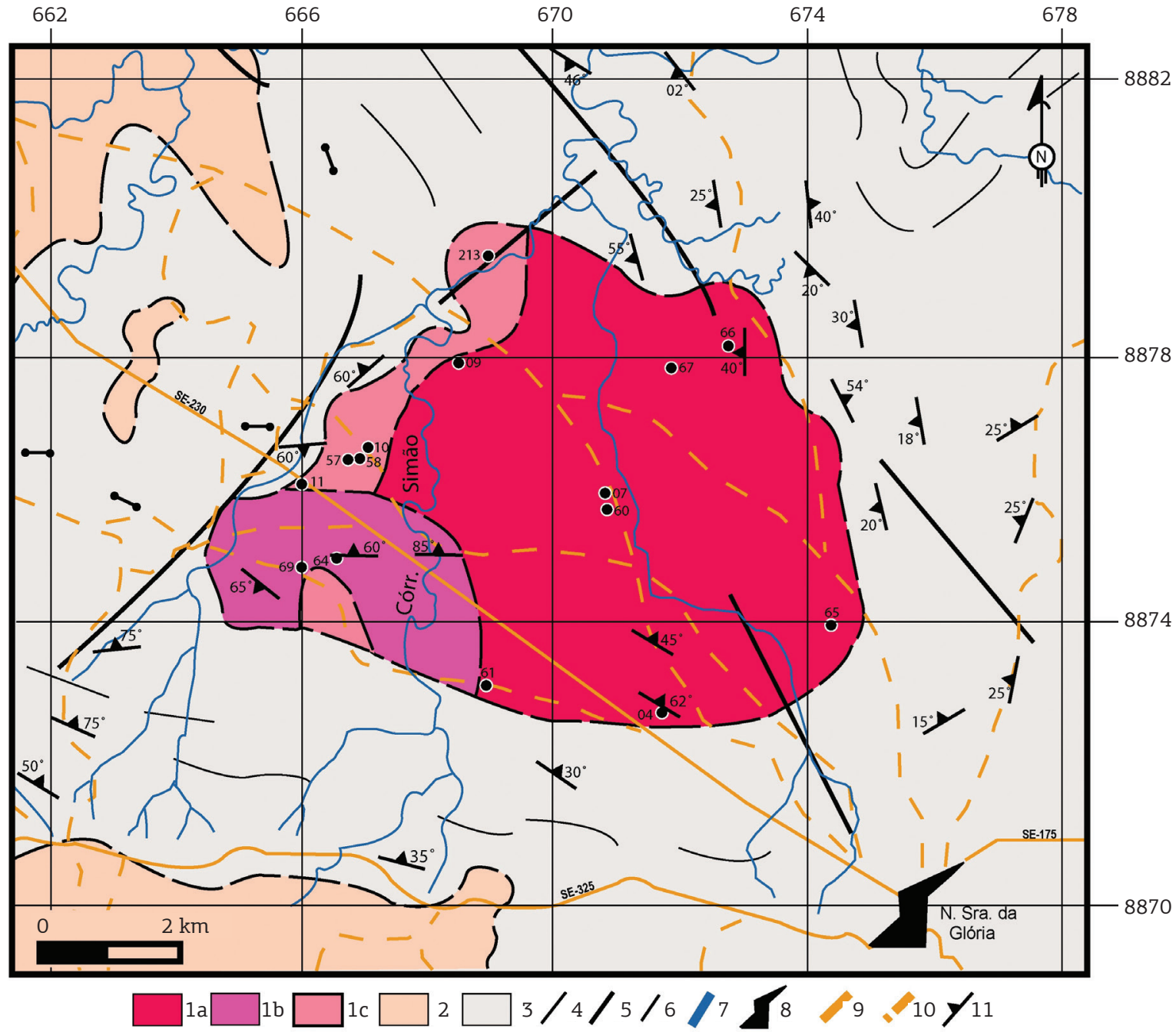

1: Stock Glória Sul 1a = sienogranitos com muscovita e biotita; $1 \mathrm{~b}=$ muscovita sienogranitos; $1 \mathrm{c}=$ biotita sienogranitos:; 2 : monzonitos; 3 : metassedimentos do Domínio Macururé; 4: contatos geológicos inferidos por fotointerpretação; 5: fraturas; 6: lineamentos fotográficos; 7: drenagens; 8: sede municipal; 9: estradas pavimentadas; 10: estradas não pavimentadas; 11: foliação. Afloramentos amostrados círculos pretos: e os números correspondem às amostras estudadas.

Figura 3. Mapa geológico simplificado do Stock Glória Sul. 
indica que as condições metamórficas atingiram a fácies hornblenda hornfels (Conceição 2014).

Internamente no SGS identificou-se a presença de quatro tipos de granitos que foram nomeados segundo os critérios

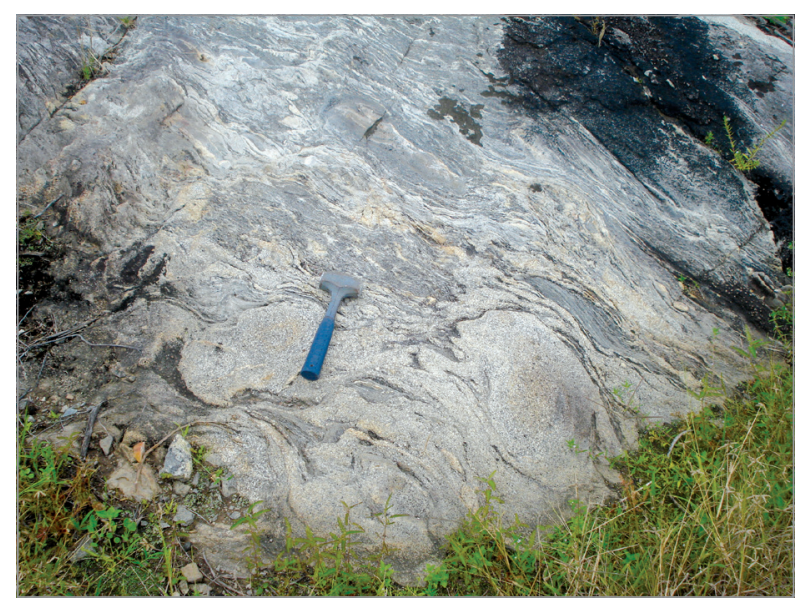

Figura 4. Contato a leste do Stock. As rochas de coloração clara correspondem aos diques de biotita monzogranito com granada. Estruturas de mobilidade nos metassedimentos indicam fusão parcial (cor cinza). da International Union of Geological Sciences (IUGS) (Le Maître et al. 2002) como: sienogranitos com muscovita, biotita e muscovita sienogranito; biotita sienogranito (Figs. 3 e 5). $\mathrm{Na}$ forma de diques tem-se biotita monzogranito com granada. Os contatos entre os tipos de granitos não foram identificados em campo e eles foram inferidos com base na disposição dos afloramentos visitados.

\section{PETROGRAFIA}

A classificação modal das rochas foi feita baseando-se na contagem média de 2.500 pontos por lâmina delgada (Fig. 5).

Os sienogranitos com muscovita e biotita são hololeucocráticos, ocupam as regióes central e leste e são aqueles que apresentam maior área no SGS (Fig. 3). Caracterizam-se por exibir uma coloração clara, granulação média, textura equigranular, estrutura isotrópica e, ocasionalmente, anisotrópica devido à presença de fluxo magmático ou de zonas de cisalhamento. Uma feição comum a esse grupo de granitos é a abundância de enclaves surmicáceos e, ocasionalmente, enclaves máficos microgranulares, os quais mostram-se orientados segundo

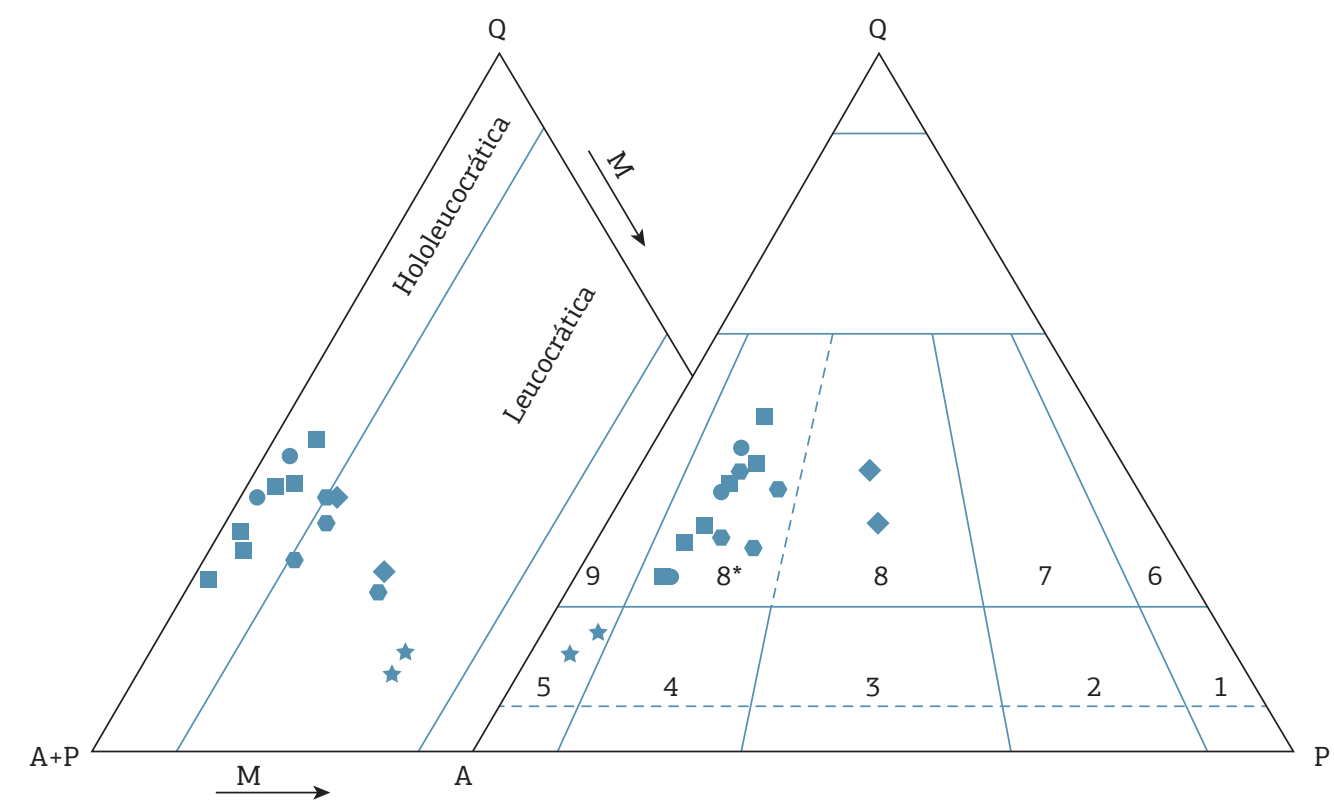

Q: quartzo, A: feldspato alcalino + albita com < 5\% anortita, P: plagioclásio (anortita > 5\%), M: total de minerais máficos. Sienogranitos com muscovita e biotita (quadrado), muscovita sienogranitos (círculo), biotita sienogranitos (hexágono), biotita monzogranito com granada (losango) e enclaves (estrelas). 1: Quartzo diorito/quartzo gabro; 2: quartzo monzodiorito; 3: quartzo monzonito; 4: quartzo sienito; 5: álcali-feldspato quartzo sienito; 6: tonalito; 7: granodiorito; 8: monzogranito; 8*: sienogranito ; 9: álcali granito.

Figura 5. Classificação das rochas plutônicas estudadas nos diagramas QAP e Q(A + P)M de Streckeisen (1976). 
o fluxo magmático. Os feldspatos presentes são pertíticos e antipertíticos, subédricos e incluem cristais de apatita, titanita, zircão e minerais opacos. Os cristais de plagioclásio $(8 \% \mathrm{An})$ sistematicamente exibem região central alterada para saussurita, contrastando com periferia límpida sem alteração, sugerindo presença de zonação composicional. Em algumas rochas a muscovita ocorre como fenocristal (até 2,2 $\mathrm{mm}$ ) e guarda inclusóes de biotita, apatita, titanita e minerais opacos.

Os muscovita sienogranitos são hololeucocráticos e o segundo grupo é mais abundante, localizando-se na porção sudoeste do SGS (Fig. 3). Eles caracterizam-se por exibir coloração clara, granulação fina a média (Fig. 6) e em vários afloramentos tem-se a presença de foliação tectônica que orienta os cristais de muscovita e deforma parcialmente os cristais de quartzo e feldspatos. Os feldspatos são anédricos, pertíticos e antipertíticos, existindo dominância da albita, que ocasionalmente é mirmequítica. Eles hospedam inclusóes de apatita, quartzo, titanita, zircão e, raramente, minerais opacos. Nessas rochas os cristais de quartzo mostram-se deformados, exibindo textura em ribbon, sendo responsável, com a muscovita, pelo desenvolvimento da foliação protomilonítica. Ao redor dos cristais de feldspatos desenvolvem-se subgrãos, gerando matriz tectônica que não atinge 5\% do volume da rocha.

Os biotita sienogranitos são leucocráticos e ocorrem de forma localizada na parte noroeste do Stock (Fig. 3). Apresentam granulação fina, textura inequigranular, coloraçáo cinza, estrutura isotrópica, sendo visível em alguns afloramentos foliação de fluxo magmático orientando enclaves máficos microgranulares elipsoides (Fig. 7). Apresentam como minerais máficos diopsídio, hornblenda e o predomínio da biotita

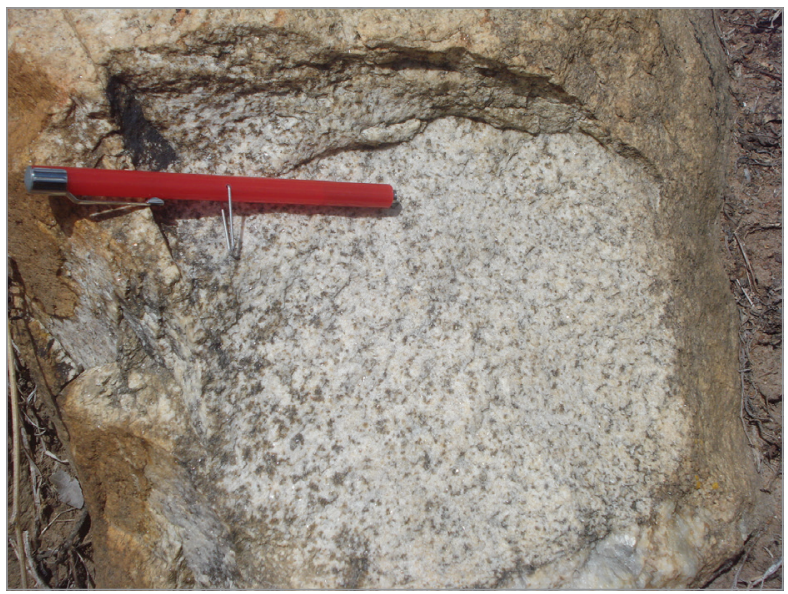

Figura 6. Textura geral dos muscovita sienogranitos, observando a orientação dos cristais de muscovita. (até 22\% volume), a qual inclui apatita acicular, zircão, titanita e minerais opacos. Os cristais de albita-oligoclásio apresentam zonação composicional múltipla bem desenvolvida e incluem apatita acicular, epídoto, titanita, zircão e minerais opacos. Epídoto magmático ocorre igualmente incluído em cristais de biotita e distribuído aleatoriamente na rocha.

Os biotita monzogranitos com granada são leucocráticos (Fig. 5) e ocorrem como diques $(<40 \mathrm{~cm}$ de espessura) na porção norte do Stock e nos metassedimentos encaixantes (Fig. 3). Eles exibem coloração cinza, mas em algumas áreas a coloração alterna para bege claro, e apresentam granulação grossa, textura inequigranular e estrutura isotrópica (Conceição 2014). A biotita é o mineral máfico dominante, com inclusôes euédricas de apatita e zircão. A granada ocorre como cristais anédricos em contato com feldspato alcalino e biotita, perfazendo um volume de $1,5 \%$ na rocha.

Os enclaves máficos microgranulares correspondem a álcali-sienitos (Fig. 5) e ocorrem essencialmente nos biotita sienogranitos, existindo de forma subordinada nos sienogranitos com muscovita e biotita. Apresentam granulação fina, são isotrópicos, usualmente apresentam borda mais escura enriquecida em biotita, e alguns deles são múltiplos e incluem outros enclaves. Albita ( $3 \%$ An) antipertítica e microclina subédricas incluem apatita acicular, titanita, biotita e zircão. Os minerais máficos presentes são diopsídio (inclui minerais opacos, apatita acicular e titanita), hornblenda (inclui minerais opacos, titanita e apatita) e biotita (inclui minerais opacos, zircão e titanita). Longos cristais aciculares de apatita $(0,2 \mathrm{~mm}$ comprimento e alongamento até $50 \mathrm{~mm}$ ) são bem distribuídos nessas rochas e refletem taxa de resfriamento rápida, responsável pela sua granulação fina.

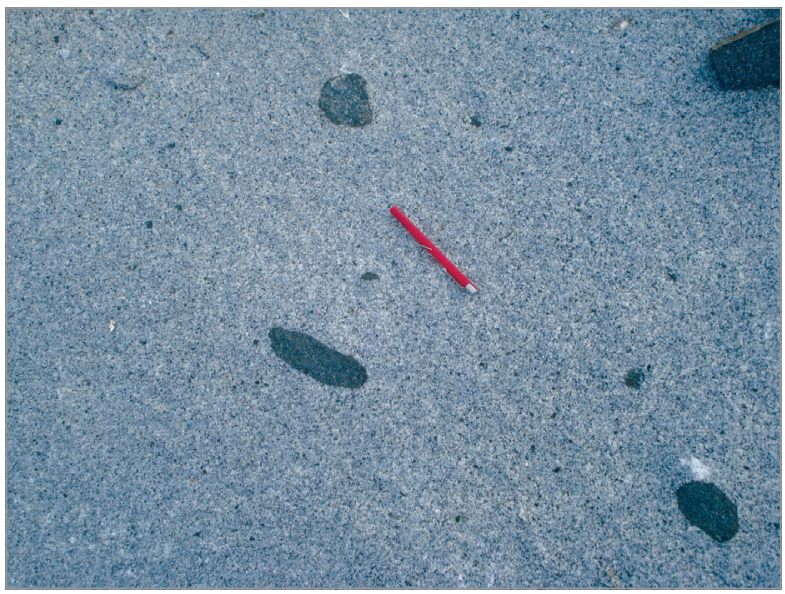

Figura 7. Textura geral dos biotita sienogranitos com a ocorrência de enclaves máficos microgranulares. 
Tabela 1. Análises geoquímicas de amostras representativas do Stock Granítico Glória Sul.

\begin{tabular}{|c|c|c|c|c|c|c|c|c|c|c|c|c|c|c|}
\hline \multirow{2}{*}{ (\%peso) } & \multicolumn{2}{|c|}{ Enclaves } & \multicolumn{2}{|c|}{ BMgG } & \multicolumn{2}{|c|}{ BSg } & \multicolumn{6}{|c|}{ SgMB } & \multicolumn{2}{|c|}{ MSg } \\
\hline & 58 & $10 \mathrm{~B}$ & 67 & 09 B & $10 \mathrm{~A}$ & 11 & 66 & 65 & 07 & 60 & 04 & 61 & 69 & 64 \\
\hline $\mathrm{SiO}_{2}$ & 56,38 & 59,40 & 66,01 & 72,80 & 68,60 & 69,15 & 70,62 & 70,97 & 71,24 & 71,31 & 72,97 & 73,04 & 72,73 & 73,19 \\
\hline $\mathrm{TiO}_{2}$ & 0,98 & 0,88 & 0,68 & 0,32 & 0,31 & 0,30 & 0,20 & 0,22 & 0,19 & 0,18 & 0,08 & 0,07 & 0,09 & 0,07 \\
\hline $\mathrm{Al}_{2} \mathrm{O}_{3}$ & 14,63 & 13,82 & 15,56 & 14,26 & 15,28 & 15,44 & 15,23 & 15,81 & 15,65 & 15,86 & 15,24 & 15,54 & 15,37 & 14,95 \\
\hline $\mathrm{Fe}_{2} \mathrm{O}_{3}$ & 5,65 & 5,76 & 4,96 & 2,57 & 2,47 & 2,30 & 1,36 & 0,97 & 1,23 & 1,02 & 0,85 & 0,79 & 0,64 & 1,02 \\
\hline $\mathrm{MnO}$ & 0,11 & 0,12 & 0,09 & 0,02 & 0,04 & 0,04 & 0,02 & 0,02 & 0,01 & 0,01 & 0,02 & 0,01 & 0,01 & 0,01 \\
\hline $\mathrm{MgO}$ & 4,11 & 4,15 & 2,50 & 0,90 & 1,10 & 1,05 & 0,32 & 0,38 & 0,29 & 0,26 & 0,14 & 0,11 & 0,12 & 0,10 \\
\hline $\mathrm{CaO}$ & 5,46 & 4,50 & 3,16 & 2,00 & 2,10 & 1,90 & 1,18 & 1,14 & 1,04 & 0,95 & 0,96 & 1,11 & 0,80 & 0,69 \\
\hline $\mathrm{Na}_{2} \mathrm{O}$ & 4,31 & 2,48 & 3,42 & 4,56 & 4,14 & 4,21 & 4,53 & 4,32 & 4,61 & 4,67 & 4,53 & 4,28 & 4,52 & 4,50 \\
\hline $\mathrm{K}_{2} \mathrm{O}$ & 5,05 & 7,05 & 2,25 & 1,57 & 4,88 & 4,78 & 5,02 & 4,95 & 5,15 & 5,16 & 4,42 & 4,40 & 4,84 & 4,62 \\
\hline $\mathrm{P}_{2} \mathrm{O}_{5}$ & 0,58 & 0,52 & 0,26 & 0,06 & 0,14 & 0,14 & 0,07 & 0,09 & 0,07 & 0,08 & 0,02 & 0,02 & 0,05 & 0,03 \\
\hline LOI & 2,30 & 0,90 & 0,80 & 0,08 & 0,70 & 0,40 & 1,00 & 0,90 & 0,30 & 0,30 & 0,70 & 0,50 & 0,70 & 0,70 \\
\hline Total & 99,56 & 99,58 & 99,69 & 99,86 & 99,76 & 99,71 & 99,75 & 99,77 & 99,78 & 99,80 & 99,93 & 99,87 & 99,87 & 99,88 \\
\hline $\mathrm{Cr}$ & 0,049 & 0,048 & 0,014 & 0,008 & 0,008 & 0,007 & $<0,002$ & $<0,002$ & $<0,002$ & $<0,002$ & $<0,002$ & $<0,002$ & $<0,002$ & $<0,002$ \\
\hline $\mathrm{Ni}$ & 47,6 & 74,4 & 18,1 & 15,2 & 14,5 & 13,5 & 1,7 & 5,7 & 2,1 & 1,0 & 1,7 & 1,7 & 1,3 & 0,9 \\
\hline Co & 20,8 & 17,9 & 11,6 & 5,9 & 5,3 & 4,9 & 1,6 & 5,5 & 1,8 & 1,5 & 1,3 & 0,6 & 1,0 & 1,0 \\
\hline Sc & 12,0 & 13,0 & 11,0 & 5,0 & 5,0 & 4,0 & 1,0 & 1,0 & 1,0 & 1,0 & 2,0 & 1,0 & 1,0 & 1,0 \\
\hline V & 119 & 103 & 91,0 & 43,0 & 36,0 & 33,0 & 14,0 & 17,0 & 15,0 & 11,0 & $<8,0$ & $<8,0$ & $<8,0$ & $<8,0$ \\
\hline $\mathrm{Cu}$ & 10 & 98,7 & 17,2 & 5,8 & 8,0 & 9,5 & 5,0 & 1,5 & 3,9 & 2,6 & 2,7 & 1,7 & 0,8 & 3,5 \\
\hline $\mathrm{Pb}$ & 9,9 & 8,8 & 3,4 & 5,6 & 4,2 & 3,5 & 26,3 & 23,6 & 4,0 & 4,5 & 10,1 & 6,5 & 44,5 & 34,2 \\
\hline $\mathrm{Zn}$ & 108 & 96,0 & 77,0 & 31,0 & 51,0 & 50,0 & 24,0 & 22,0 & 48,0 & 42,0 & 6,0 & 7,0 & 7,0 & 6,0 \\
\hline $\mathrm{Ba}$ & 1155 & 1179 & 944 & 490 & 1052 & 1060 & 944 & 1018 & 911 & 940 & 319 & 567 & 631 & 511 \\
\hline $\mathrm{Rb}$ & 281,1 & 351 & 99,6 & 55,3 & 207,1 & 191,8 & 204,8 & 209,4 & 241,2 & 227,8 & 235,5 & 187,0 & 238,9 & 220,3 \\
\hline $\mathrm{Sr}$ & 589,7 & 503,1 & 504,5 & 394,6 & 668,3 & 693,5 & 491,1 & 528,7 & 466,6 & 443,9 & 183,6 & 313,5 & 293,3 & 270,8 \\
\hline Ga & 22,5 & 19,7 & 20,5 & 14,7 & 22,7 & 21,1 & 25,8 & 25,3 & 27,3 & 24,4 & 30,2 & 23,1 & 26,8 & 25,4 \\
\hline $\mathrm{Zr}$ & 224,2 & 222,3 & 172,9 & 109,8 & 145,1 & 144,8 & 146,3 & 135,7 & 129,3 & 120,8 & 54,2 & 58,8 & 76,4 & 67,9 \\
\hline $\mathrm{Y}$ & 15,8 & 16,7 & 15,3 & 9,6 & 7,8 & 8,2 & 4,4 & 7,1 & 1,8 & 1,6 & 4,4 & 5,5 & 2,7 & 2,4 \\
\hline Cs & 26,1 & 28,2 & 6,2 & 1,6 & 15,1 & 12,8 & 8,4 & 6,7 & 13,4 & 9,9 & 9,4 & 13,5 & 19,5 & 16,0 \\
\hline $\mathrm{Nb}$ & 11,6 & 12,8 & 8,3 & 20,8 & 7,6 & 7,3 & 4,4 & 5,0 & 4,6 & 3,4 & 6,7 & 5,0 & 4,8 & 4,4 \\
\hline $\mathrm{U}$ & 10,4 & 10,6 & 1,6 & 2,8 & 6,8 & 4,9 & 3,3 & 2,6 & 4,3 & 3,2 & 3,7 & 3,8 & 4,4 & 4,6 \\
\hline $\mathrm{La}$ & 66,1 & 51,1 & 27,7 & 14,9 & 30,2 & 41,9 & 29,3 & 28,9 & 24,7 & 16,0 & 9,0 & 8,0 & 10,4 & 8,7 \\
\hline $\mathrm{Ce}$ & 130,3 & 113,6 & 54,1 & 32,6 & 63,1 & 78,6 & 58,1 & 57,9 & 48,2 & 34,1 & 18,3 & 14,1 & 20,0 & 19,3 \\
\hline $\mathrm{Nd}$ & 60,4 & 54,2 & 24,5 & 13,9 & 27,7 & 33,9 & 23,3 & 26,6 & 18,0 & 12,4 & 9,1 & 7,8 & 9,1 & 6,7 \\
\hline $\mathrm{Sm}$ & 10,13 & 8,92 & 4,69 & 2,5 & 4,39 & 5,2 & 3,82 & 4,86 & 2,71 & 2,14 & 2,13 & 1,97 & 1,95 & 1,72 \\
\hline $\mathrm{Eu}$ & 2,52 & 2,35 & 1,30 & 1,47 & 1,08 & 1,2 & 0,79 & 1,01 & 0,66 & 0,53 & 0,43 & 0,53 & 0,47 & 0,43 \\
\hline $\mathrm{Gd}$ & 6,74 & 6,22 & 3,88 & 2,18 & 2,85 & 3,28 & 2,43 & 3,19 & 1,23 & 1,11 & 1,58 & 1,66 & 1,28 & 1,11 \\
\hline
\end{tabular}


Tabela 1. Continuação.

\begin{tabular}{|c|c|c|c|c|c|c|c|c|c|c|c|c|c|c|}
\hline \multirow{2}{*}{ (\%peso) } & \multicolumn{2}{|c|}{ Enclaves } & \multicolumn{2}{|c|}{ BMgG } & \multicolumn{2}{|c|}{ BSg } & \multicolumn{6}{|c|}{ SgMB } & \multicolumn{2}{|c|}{ MSg } \\
\hline & 58 & $10 \mathrm{~B}$ & 67 & 09 B & $10 \mathrm{~A}$ & 11 & 66 & 65 & 07 & 60 & 04 & 61 & 69 & 64 \\
\hline $\mathrm{Tb}$ & 0,79 & 0,82 & 0,57 & 0,35 & 0,38 & 0,4 & 0,26 & 0,34 & 0,12 & 0,1 & 0,21 & 0,21 & 0,13 & 0,13 \\
\hline Dy & 3,53 & 3,45 & 3,27 & 1,76 & 1,53 & 1,76 & 1,05 & 1,45 & 0,37 & 0,4 & 0,88 & 1,21 & 0,62 & 0,42 \\
\hline Ho & 0,52 & 0,55 & 0,55 & 0,31 & 0,24 & 0,25 & 0,13 & 0,2 & 0,05 & 0,04 & 0,12 & 0,18 & 0,07 & 0,07 \\
\hline Er & 1,33 & 1,48 & 1,43 & 0,81 & 0,61 & 0,69 & 0,32 & 0,58 & 0,11 & 0,12 & 0,31 & 0,43 & 0,21 & 0,12 \\
\hline $\mathrm{Tm}$ & 0,21 & 0,21 & 0,19 & 0,13 & 0,1 & 0,1 & 0,05 & 0,08 & 0,02 & 0,02 & 0,05 & 0,06 & 0,02 & 0,02 \\
\hline $\mathrm{Yb}$ & 1,19 & 1,28 & 1,14 & 0,79 & 0,66 & 0,63 & 0,34 & 0,5 & 0,12 & 0,14 & 0,26 & 0,4 & 0,17 & 0,1 \\
\hline $\mathrm{Lu}$ & 0,17 & 0,17 & 0,16 & 0,12 & 0,08 & 0,09 & 0,04 & 0,06 & 0,02 & 0,01 & 0,04 & 0,05 & 0,01 & 0,01 \\
\hline $\mathrm{Ta}$ & 0,6 & 0,7 & 0,5 & 0,8 & 0,5 & 0,5 & 0,4 & 0,5 & 0,3 & 0,3 & 0,7 & 0,4 & 0,5 & 0,4 \\
\hline $\mathrm{Hf}$ & 6,0 & 6,3 & 4,4 & 3,5 & 4,4 & 4,6 & 4,9 & 4,6 & 3,9 & 3,4 & 2,4 & 2,7 & 3,2 & 3,6 \\
\hline Th & 17,6 & 17,9 & 10,3 & 5,7 & 16,1 & 13,4 & 19,7 & 14,2 & 18,7 & 15,2 & 7,5 & 6,3 & 10,1 & 8,4 \\
\hline W & $<0,5$ & $<0,5$ & $<0,5$ & 4,0 & $<0,5$ & $<0,5$ & $<0,5$ & $<0,5$ & $<0,5$ & $<0,5$ & $<0,5$ & $<0,5$ & $<0,5$ & $<0,5$ \\
\hline Mo & 1,5 & 0,6 & 0,6 & 0,7 & 0,5 & 0,4 & 0,1 & $<0,1$ & 0,4 & 0,1 & 0,3 & $<0,1$ & 0,1 & 0,4 \\
\hline$\Sigma$ ETR & 299,21 & 257,82 & 129,69 & 75,38 & 139,98 & 177,24 & 126,27 & 132,35 & 101,51 & 70,57 & 44,61 & 38,58 & 46,79 & 40,73 \\
\hline$(\mathrm{La} / \mathrm{Yb})_{\mathrm{N}}$ & 37,03 & 26,61 & 16,2 & 12,57 & 30,51 & 44,34 & 57,45 & 38,53 & 137,22 & 76,19 & 23,08 & 13,33 & 40,78 & 58,00 \\
\hline $\mathrm{Eu} / \mathrm{Eu}^{*}$ & 0,94 & 0,97 & 0,94 & 1,94 & 0,94 & 0,89 & 0,80 & 0,79 & 1,11 & 1,06 & 0,72 & 0,90 & 0,91 & 0,96 \\
\hline
\end{tabular}

BMgG: biotita monzogranito com granada; BSg: biotita sienogranito; SgMB: sienogranito com muscovita e biotita; MSg: muscovita sienogranito.

\section{GEOQUÍMICA}

Foram feitas 14 análises geoquímicas em amostras representativas do SGS (Tab. 1), sendo 6 de sienogranitos com muscovita e biotita, 2 de muscovita sienogranitos, 2 de biotita sienogranitos, 2 nos monzogranitos com granada e 2 outras de enclaves máficos microgranulares (MME).

As análises geoquímicas foram realizadas na Acme Labs, no Canadá, utilizando-se o pacote Geo3 (Grupos 4A e 4B) conveniente para estudos petrológicos. Nesse pacote analítico os elementos maiores foram dosados por Inductively Coupled Plasma Optical Emission Spectrometry (ICP-OES), e os elementos menores e traços, por Inductively Coupled Plasma Microespectrometry (ICP-MS), sendo a precisão de $2 \%$ para os elementos maiores e de $2 \%$ para os elementos traços.

As amostras estudadas são peraluminosas $(0,2<$ coríndon normativo $\left._{\mathrm{CIPW}}<2,4\right)$, exceto aquelas dos MME e dos biotita sienogranitos, que são metaluminosas (Fig. 8A). Os granitos com granada destacam-se do conjunto peraluminoso pela maior razão molecular $\mathrm{Al}_{2} \mathrm{O}_{3} /\left(\mathrm{Na}_{2} \mathrm{O}+\mathrm{K}_{2} \mathrm{O}\right)$ e por conteúdos mais elevados de $\mathrm{CaO}(2,0-3,1 \%)$. Umas poucas amostras do SGS posicionam-se no campo dos granitos do tipo $S$, de Chappell e White (1992), e essas correspondem aos granitos com granada e a alguns muscovita granitos mais evoluídos.
Os granitos estudados são subalcalinos e posicionamse no campo das rochas cálcio-alcalinas de alto potássico (Fig. 8B), similar ao que ocorre com leucogranitos de sistemas orogênicos paleoproterozoicos do Cráton Sáo Francisco (e.g. Rudowski 1989; Cuney et al. 1990). Os monzogranitos com granada alocam-se no campo das suítes cálcio-alcalinas de médio potássio, mostrando-se com afinidade distinta dos outros granitos do SGS. Os MME posicionam-se no campo das suítes shoshoníticas. A presença de rochas com afinidades magmáticas distintas no SGS indicam que nesse Stock coexistiram diferentes magmas quando de sua estruturação.

Os $\mathrm{MME}$, com $\mathrm{SiO}_{2}$ variando de 56,38 a 59,40\%, são as rochas menos diferenciadas do Stock e apresentam o maior somatório de ETR, $257<$ ETR (ppm) < 300, e padrôes com forte fracionado em ETRLeves: $26<$ [La/ $\mathrm{Yb}]_{\mathrm{N}}<37$ (Fig. 9A). Eles exibem fracas anomalias negativas em Eu $(0,94-0,97)$, característica comum das rochas shoshoníticas, segundo Morrison (1980). Essas rochas são similares àquelas do SGS, mas com maiores conteúdos em ppm de: Ba (1.155 - 1.179), Zr (222 - 224), Hf (6,0 $6,3), Y(15,8-16,7)$, Cs $(26,1-28,2), V(103-119), Z n$ (96 - 108), U $(10,4-10,6)$ e Th $(17,6-17,9)$. Os baixos valores de $\mathrm{MgO}(4,11-4,15 \%)$, Ni (47,6 - 74,4 ppm) e 
$\mathrm{Cr}$ (> $1 \mathrm{ppm})$ indicam que esses sienitos formaram-se a partir de um magma traquítico evoluído.

Os biotita sienogranitos $\left(68,6-69,15 \% \mathrm{SiO}_{2}\right)$, com total de ETR variando de 139,98 a 177,24 ppm, exibem fracionamento nos ETRLeves, 30,51 $<[\mathrm{La} / \mathrm{Yb}]_{\mathrm{N}}<44,34$, e fraca anomalia negativa em Eu $(0,89-0,94)$. Os conteúdos são mais baixos que os MME em ETR (177,24 139,98 ppm), Ba (1052 - 1060 ppm), Zr (145 ppm), Hf (4,4-4,6 pmm), Y (7,8 - 8,2 ppm), Cs (12,8-15,1 ppm). Percebe-se que os ETR pesados (Ho-Lu) são menores que os MME, adquirem aplainamento, sugerindo fracionamento de fases acessórias (Fig. 9B).

Os sienogranitos com muscovita e biotita $(70,62-73,04 \%$ $\mathrm{SiO}_{2}$ ) apresentam espectros de ETR com grande variação de fracionamento, 13,3 $<[\mathrm{La} / \mathrm{Yb}]_{\mathrm{N}}<137,22$ (Fig. 9C), total de ETR variando de 38,58 a 132,35 ppm, e anomalia em Eu variando de fracamente negativa $(0,72)$ a fracamente positiva $(1,11)$. Os conteúdos dos elementos traços em ppm variam nos intervalos: $\mathrm{Ba}(319-1018), \mathrm{Zr}(54-146)$, Hf $(2,4-$ $4,9), \mathrm{Y}(1,6-7,1), \mathrm{Cs}(6,7-13,5), \mathrm{V}(<8-17), \mathrm{Zn}(6-48)$, $\mathrm{U}(2,6-4,3)$ e Th $(6,3-19,7)$. As semelhanças geométricas entre os três conjuntos de espectros dessas rochas do SGS (MME, biotita sienogranitos, sienogranitos com muscovita e biotita) sugerem que elas tenham relações genéticas.

Os muscovita sienogranitos $\left(72,73-73,19 \% \mathrm{SiO}_{2}\right)$ apresentam espectros de ETR fracionados, $40<[\mathrm{La} / \mathrm{Yb}]_{\mathrm{N}}<58$, e anomalias sutis em $\mathrm{Eu}(0,90$ - 0,96) (Fig. 9D). Os conteúdos dos elementos traços em ppm são: Ba (511 - 631),
$\mathrm{Zr}(67,9-67,9)$, Hf $(3,2-3,6)$, Y $(2,4-2,7)$, Cs (1619,5), V (<8), Zn (6 - 7), U (4,4-4,6) e Th $(8,4-10,1)$.

Os biotita monzogranitos com granada $(66,01-72,8 \%$ $\mathrm{SiO}_{2}$ ) apresentam espectros ETR fracionados (Fig. 9E). Essas rochas têm total ETR variando de 75,38 a 129,69 ppm, baixo fracionamento em ETR, 12,57 $<[\mathrm{La} / \mathrm{Yb}]_{\mathrm{N}}<16,2$, e anomalia em Eu positiva $(1,94)$ na amostra mais evoluída $\left(72,8 \% \mathrm{SiO}_{2}\right)$ a fracamente negativa $(0,94)$ na amostra menos evoluída $\left(66,01 \% \mathrm{SiO}_{2}\right)$. Os conteúdos em ppm de elementos traços nesse grupo são: $\mathrm{Ba}(490$ - 944), $\mathrm{Zr}(109,8$ - 172,9), Hf $(3,5-4,4), Y(9,6-15,3)$, Cs $(1,6-6,2)$, V (43-91), Zn (31 - 77), U (1,6 - 2,8) e Th $(5,7$ - 10,3). A geometria dos espectros dos ETR desse grupo sugere que o magma gerador dessas rochas seja distinto daqueles envolvidos na formação dos sienogranitos e MME.

\section{DISCUSSÃO}

Os vários trabalhos recentes desenvolvidos em granitos no DM (Oliveira 2014; Silva 2014; Mendonça 2013; Oliveira et al. 2015) revelam que eles náo correspondem a granitos típicos do tipo S (Fig. 8A), como descrito por Chappell e White (1992). Os baixos conteúdos de coríndon normativo $_{\text {CIPW }}$ e a ausência de minerais peraluminosos característicos (e.g. cordierita, sillimanita, granada etc.) sugerem que esses granitos tenham importante contribuição de fontes quartzo-feldspáticas e não metapelíticas.
A

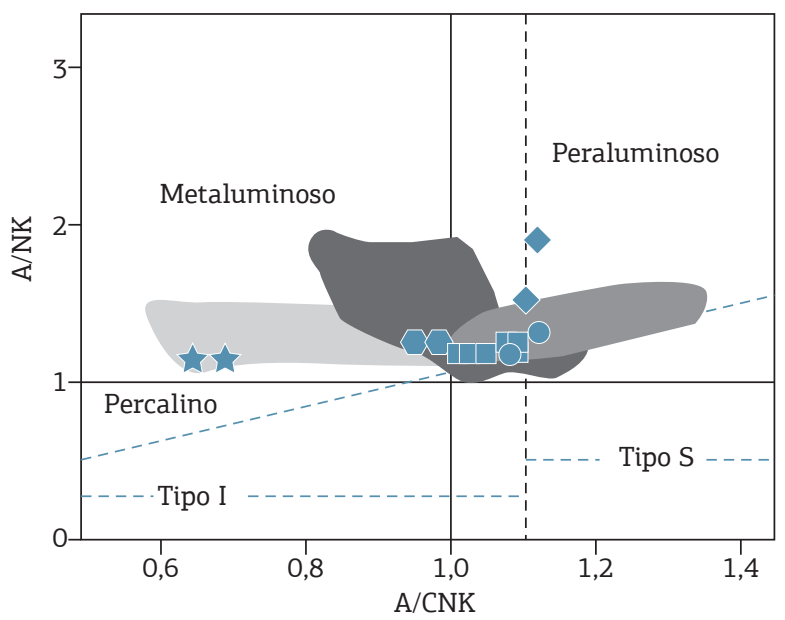

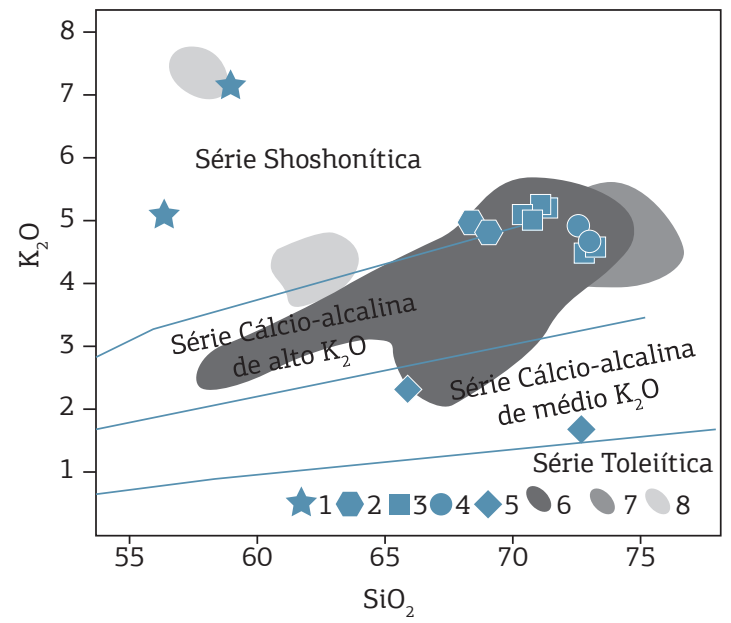

1: Enclaves máficos microgranulares; 2: biotita sienogranitos; 3: sienogranitos com muscovita e biotita; 4: muscovita sienogranitos e 5: biotita monzogranitos com granada; 6: área ocupada pelos granitos do Domínio Macururé, de Oliveira et al. (2015); 7: área ocupada pelos leucogranitos dos sistemas orogênicos paleoproterozoicos do Cráton São Francisco, após Rudowski (1989) e Cuney et al. (1990); 8: e monzonitos shoshoníticos do Stock Glória Norte, segundo Lisboa (2014).

Figura 8. Diagramas A/NK versus A/CNK (A), de Maniar e Piccoli (1989), e $\mathrm{K}_{2} \mathrm{O}$ versus $\mathrm{SiO}_{2}(\mathrm{~B})$, de Peccerillo e Taylor (1976), aplicados às rochas estudadas. A delimitação dos campos de granitos dos tipos S e I, segundo Chappell e White (1992). 
A presença de MME em granitos é usualmente interpretada como evidência de mistura entre magmas máfico e félsico (e.g. Barbarin 2005). No caso do SGS, os enclaves são mais abundantes nos biotita sienogranitos, que correspondem às rochas menos evoluídas dentre os granitos. Esses enclaves de composição sienítica, com formas elipsoides, estão orientados segundo o fluxo magmático. Eles não exibem texturas de acumulação e têm granulação mais fina que os granitos encaixantes. Essas feiçóes indicam que eles representam porçôes de magmas que tiveram cristalização mais rápida que o biotita sienogranito encaixante. A presença abundante de cristais de apatita acicular nessas rochas, associada a feiçóes de instabilidades nos cristais de plagioclásio (zonação, corrosão), contribui para a hipótese de mistura entre magmas.
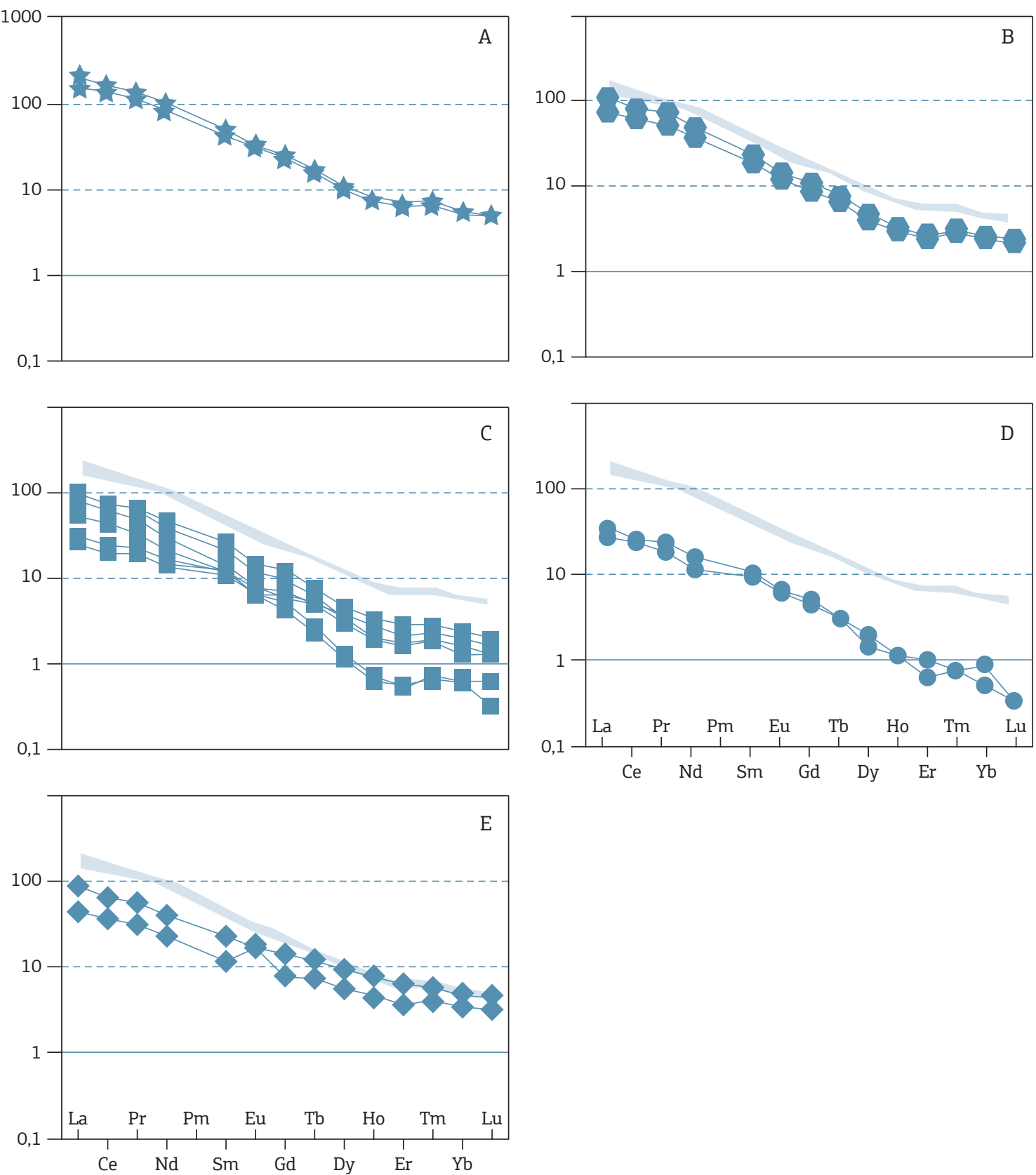

Figura 9. Espectros dos ETR das rochas estudadas normalizados pelos valores de condritos segundo Evensen et al. (1978). Enclaves máficos microgranulares (A), biotita sienogranitos (B), sienogranitos com muscovita e biotita (C), muscovita sienogranitos (D) e biotita monzogranitos com granada (E). A área azul clara apresentada corresponde aos espectros dos enclaves. 
Ocorrência de magmas shoshoníticos no SOS tem sido descrita nos domínios Marancó, Canindé e Poço Redondo (Santos et al. 1988; Brito et al. 2009; Gentil 2013) e a idade desse magmatismo situa-se entre 611 e $615 \mathrm{Ma}$ (Gava et al. 1983; Brito et al. 2009; Silva Filho et al. 2013). Lisboa (2014) descreve a presença de magmatismo shoshonítico (monzonitos e sienito) no DM e apresenta a idade de cristalização de $588 \pm$ 5,2 Ma (U-Pb Shrimp) para o Stock Glória Norte. Esse dado evidencia a presença de, no mínimo, dois períodos de magmatismo shoshonítico durante a evolução do SOS. A semelhança entre os dados geoquímicos dos MME estudados com as rochas máficas shoshoníticas no DM (Fig. 10), que situam-se a menos de $8 \mathrm{~km}$ a noroeste do SGS, sugere que elas correspondam ao mesmo magmatismo shoshonítico. Essas rochas apresentam geoquímica característica de sienitos com assinatura de subducção, ou seja, empobrecimento em $\mathrm{Ta}-\mathrm{Nb}$ - $\mathrm{Ti}$, vale em $\mathrm{Sr}$, valores elevados em ETRLeves, enriquecimento em elementos incompatíveis, fracionamento dos ETRLeves e fraca ou ausente anomalia em Eu (Thompson e Fowler 1986; Conceição 1992). Todavia, diferentemente dos sienitos orogênicos shoshoníticos, que nos diagramas de Pearce posicionam-se no campo do magmatismo de arco vulcânico, os estudados alocam-se no campo do magmatismo sin-colisional, sugerindo maior contribuição crustal.

Os muscovita sienogranitos mais evoluídos do SGS $\left(\mathrm{SiO}_{2}>72 \%\right)$ são comparáveis aos leucogranitos paleoproterozoicos do Cráton São Francisco, que igualmente não correspondem aos produtos típicos de fusão de metassedimentos.

Os dados geológicos e petrográficos apontam para o processo de mistura entre magmas na formação do SGS. Essa hipótese encontra reforço ao se observar a evolução geoquímica das rochas do SGS em diagramas binários (Fig. 11), que exibem boas correlaçóes retilíneas $\left(\mathrm{R}^{2}>0,97\right)$ entre o $\mathrm{SiO}_{2}$ e vários óxidos (e.g. $\mathrm{TiO}_{2}, \mathrm{CaO}, \mathrm{P}_{2} \mathrm{O}_{5}$ e $\mathrm{MgO}$ ) e elementos traços (e.g. Zr, ETR, Ba, Co). Observando-se esses diagramas percebe-se que as amostras se alinham entre polos extremos representados pelas amostras FDS-58, que corresponde ao MME menos evoluído (56,38\% $\mathrm{SiO}_{2}$ ), e FDS-64 (73,19\% $\mathrm{SiO}_{2}$ ), que corresponde ao muscovita sienogranito mais evoluído. Nesse modelo os biotita sienogranitos correspondem a uma taxa de mistura de $25 \%$ de magma máfico, e os sienogranitos com biotita e muscovita, a 13\% de magma máfico.

\section{CONCLUSÕES}

A forma do SGS mostra-se arredondada e trunca as foliaçóes regionais existentes no DM. Tais caraterísticas indicam ser essa intrusão claramente posterior à deformação nos metassedimentos encaixantes. $\mathrm{O}$ desenvolvimento de metamorfismo de contato chega a atingir a Fácies Hornblenda Hornfels.

A granitogênese no DM, no SOS, é realmente variada, como descrito pela literatura. A reuniáo dos dados disponíveis até o momento sobre esses granitos tornou possível identificar a existência de quatro conjuntos de corpos que são reunidos sob a terminologia, a saber:

1. granodiorítico cálcio-alcalino de alto potássio;

2. monzonítico shoshonítico;

3. sienogranítico leucocrático cálcio-alcalino de alto potássio;

4. granítico cálcio-alcalino de alto potássio com textura rapakivi.

A diversidade de tipos de sienogranitos presentes no SGS foi interpretada como sendo produto de mistura
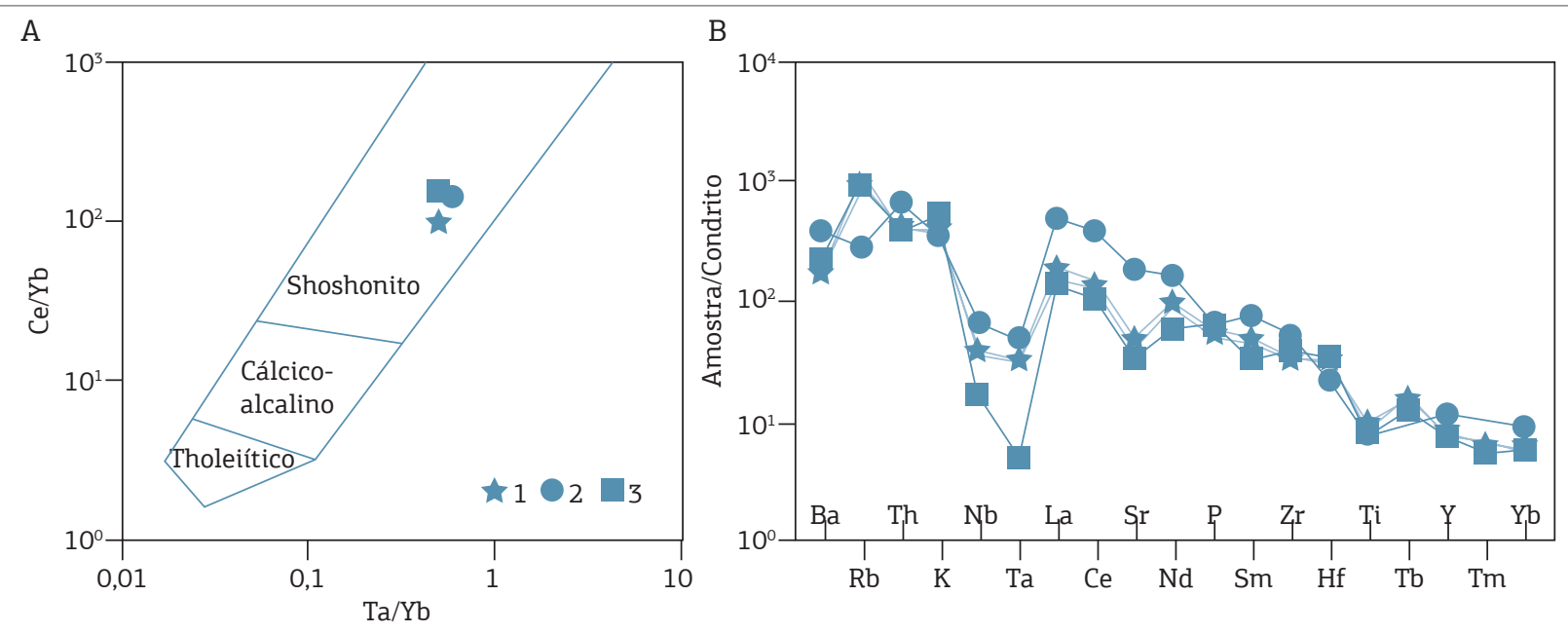

1: Enclaves estudados, 2: média dos enclaves máficos shoshoníticos do Domínio Macururé, 3: rocha máfica shoshonítica de Thompson e Fowler (1986)

Figura 10. Diagrama $\mathrm{Ce} / \mathrm{Yb}$ versus $\mathrm{Ta} / \mathrm{Yb}$ (A) com campos de Pearce (1982). Diagrama multielementar (B), normalizado pelo condrito de Thompson (1982). 
entre magmas: um mantélico, de afinidade shoshonítica, representado pelos enclaves máficos microgranulares, e outro mais evoluído, de composição sienogranítica, que ocorre como diques no Stock e nas encaixantes metassedimentares. Ante aos dados obtidos neste estudo, os sienogranitos do SGS não correspondem a granitos típicos I ou S. Eles representam rochas híbridas e de gênese complexa.

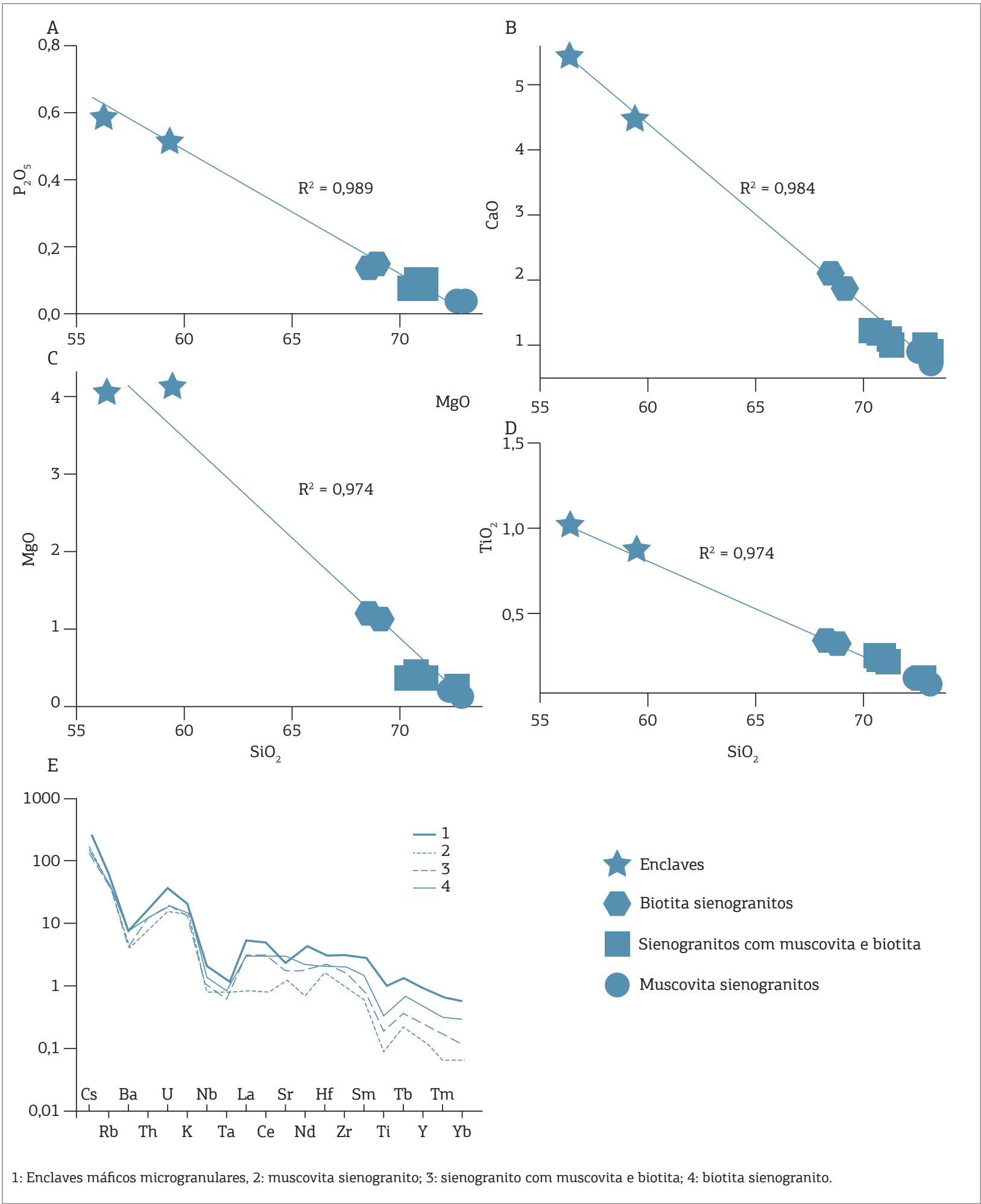

Figura 11. Diagramas binários de $\mathrm{SiO}_{2}$ versus $\mathrm{P}_{2} \mathrm{O}_{5}(\mathrm{~A}), \mathrm{CaO}(\mathrm{B}), \mathrm{MgO}(\mathrm{C})$ e $\mathrm{TiO}_{2}(\mathrm{D})$, diagrama de elementos traços normalizado pelo condrito de Thompson (1982) (E). 


\section{AGRADECIMENTOS}

Os autores agradem o suporte financeiro do Conselho Nacional de Desenvolvimento Científico e Tecnológico (CNPq) e a Fundação de Apoio à Pesquisa e à Inovação Tecnológica do Estado de Sergipe (FAPITEC), processos números: 308059/2014-0 (CNPq-PQ), 308754/2013-1 (CNPq-PQ), 473013/2012-4 (CNPq-Universal 2013) e 019.203.02538/2009-7 (PRONEX/FAPITEC/CNPq). JAC é bolsista de doutorado do CNPq (Proc. nº 141473/2014-2). Somos agradecidos a Dra. Rita Cunha Leal Menezes e a Dra. Cristina Maria Burgos Carvalho, pesquisadoras da Superintendência de Salvador da CPRM, pelas frutíferas discussôes e facilidades laboratoriais na preparação das amostras e separação de minerais. Aos revisores, Prof. Lauro Valentim Stoll Nardi e Profa. Cristina de Campos, expressamos nossos agradecimentos pelas críticas e sugestóes que enriqueceram o trabalho.

\section{REFERÊNCIAS}

Barbarin B. (2005). Mafic magmatic enclaves and mafic rocks associated with some granitoids of the central Sierra Nevada batholith, California: nature, origin, and relations with the hosts. Lithos, 80:155-177.

Borges T.E.S. (2015). Aspectos Geológicos e Petrográficos do Stock Holomonzogranito Pedra Furada, Sistema Orogênico Sergipano. (Trabalho de Conclusão de Curso). São Cristóvão: Universidade Federal de Sergipe.

Brito M.F.L., Silva Filho A.F., Guimarães I.P. (2009). Caracterização geoquímica e isotópica do Batólito Serra do Catu e sua evolução da interface dos domínios Sergipano e Pernambuco-Alagoas, Província Borborema. Revista Brasileira de Geociências, 39(2):324-337.

Brito Neves B.B., Cordani U.G. (1973). Problemas Geocronológicos do "Geossinclinal Sergipano" e do seu embasamento. In: XXVI Congresso Brasileiro de Geologia. Aracaju: Sociedade Brasileira de Geologia. Anais, 1, p. 67-76.

Bueno J.F., Oliveira E.P., McNaughton N.J., Laux J.H. (2009). U-Pb dating of granites in the Neoproterozoic Sergipano Belt, NE-Brazil: Implications for the timing and duration of continental collision and extrusion tectonics in the Borborema Province. Gondwana Research, 15:86-97.

Chappell B.W., White J.R. (1992). I- and S-type granites in the Lachlan Fold Belt. Transation of Royal Society Edinburg: Earth Sciences, 83(1-2):1-26.

Chaves J.M. (1991). Maciços Cel. João Sá e Glória: Petrologia e Geoquímica de Granitoides do Domínio Macururé, Faixa Sergipana (NE do Brasil). (Dissertação de Mestrado). Salvador: Instituto de Geociências, Universidade Federal da Bahia.

Conceição J.A. (2014). Petrologia do Stock Granítico Glória Sul, Faixa Sergipana, setor sul da Província Borborema, Sergipe. (Dissertação Pós-Graduação em Geociências e Análise de Bacias). São Cristóvão: Universidade Federal de Sergipe.

Conceição H. (1992). Petrology of syenites from the Salvador-Curaçá Mobile Belt (Bahia-Brazil): geodynamic significance. Anais da Academia Brasileira de Ciências, 65(Supl. 1):17-32.

Cuney M., Sabaté P., Vidal P., Marinho M.M., Conceição H. (1990). The 2 Ga peraluminous magmatism of the Jacobina-Contendas Mirante Belt (Bahia) Brazil: Major and trace-element geochemistry and metallogenic potential. Journal of Volcanology and Geothermal Research, 44:123-141.

Davison I., Santos R.A. (1989). Tectonic Evolution of the Sergipano Fold Belt, NE Brazil, during the Brasiliano Orogeny. Precambrian Research, 45:319-342.
D’el-Rey Silva L.J.H., McClay K.R. (1995). Stratigraphy of the southern part of the Sergipano Belt, NE Brazil: Tectonic Implications. Revista Brasileira de Geociências, 25(3):185-202

D’el-Rey-Silva L.J.H. (1999). Basin infilling in the southern-central part of the Sergipano Belt (NE Brazil) and implications for the evolution of Pan-African/Brasiliano cratons and Neoproterozoic sedimentary cover. Journal of South American Earth Sciences, 12:453-470.

Evensen N.M., Hamilton P.J., O'nions R.K. (1978). Rare-earth abundance in chondrite meteorites. Geochimica et Cosmochimica Acta, 42:1199-1212

Fujimori S. (1989). Contribuição ao estudo dos granitoides do Sistema de Dobramento Sergipano. Revista Brasileira de Geociências, 19(2):241-247

Gaston G.O., Santos R.A. (1988). Geoquímica de alguns Granitoides da Faixa de Dobramentos Sergipana. In: XXXV Congresso Brasileiro de Geologia. Belém: Sociedade Brasileira de Geologia. Anais, 3, p. 1037-1052.

Gava A., Nascimento D.A., Vidal J.L.B. (1983). Geologia. In: Projeto RADAM BRASIL: Folha SC. 24/25, Aracaju-Recife. Rio de Janeiro: Ministério das Minas e Energia. 852 p.

Gentil T.F.C. (2013). Petrologia e Geoquímica do Batólito shoshonítico Serra do Brejo no Domínio Poço Redondo, Faixa Sergipana (Sul da Província Borborema). (Dissertação de Mestrado, Pós-Graduação em Geociências e Análise de Bacias). São Cristóvão: Universidade Federal de Sergipe.

Humphrey F.L., Allard G.O. (1969). Geologia da área do Domo de Itabaiana (Sergipe) e sua relação com a geologia do geossinclinal de Propriá: um elemento tectônico recém-reconhecido no escudo brasileiro. Rio de Janeiro: PETROBRÁS/CENPES, Divisão de Documentação Técnica e Patentes. 160 p.

Jardim de Sá E.F., Moraes J.A.C., D’el-Rey Silva L.J.H. (1986). Tectônica tangencial na Faixa Sergipana. In: XXXIV Congresso Brasileiro de Geologia. Salvador: Sociedade Brasileira de Geologia. Anais, v .3, p. 1246-1259.

Le Maître R.W., Streckeisen A., Zanettin B., Le Bas M.J., Bonin B., Bateman P., Bellieni G., Dudek A., Efremova S., Keller J., Lameyre J., Sabine P.A., Schmid R., Sørensen H., Woolley A.R. (2002). Igneous Rocks - A classification and glossary of terms. Recommendations of the International Union of Geological Sciences - Subcommission on the Systematics of Igneous Rocks. $2^{\text {nd }}$ ed. New York: Cambridge University Press. 254 p.

Lisboa V.A.C. (2014). Petrologia e Geocronologia do Maciço Glória Norte, Faixa de Dobramentos Sergipana, NE do Brasil. (Dissertação de Mestrado, Pós-Graduação em Geociências e Análise de Bacias). São Cristóvão: Universidade Federal de Sergipe. 
Lisboa V.A.C., Rosa M.L.S., Conceição H., Macambira M.J.B., Galarza M.A., Rios D.C. (2014). Datação de Pb-Pb em Monozircão do Maciço Glória Norte, Faixa Sergipana. Scientia Plena, 10(6):1-4.

Long L.E., Castellana C.H., Sial A.N. (2005). Age, origin and cooling history of the Coronel João Sá Pluton, Bahia, Brazil. Journal of Petrology, 46:255-273.

Maniar, P. D., Piccoli, P. M. (1989). Tectonic discrimination of granitoids. Geological Society of America Bulletin, 101:635-643.

Melo J.P.P. (2015). Aspectos Geológicos e Petrográficos do Stock Granítico Angico, Sistema Orogênico Sergipano. (Trabalho de Conclusão de Curso). São Cristóvão: Universidade Federal de Sergipe.

Mendonça L.H. (2013). Geologia, Petrografia e Geoquímica de Stocks Graníticos no município de Canhoba, Sergipe. (Trabalho de Conclusão de Curso, Universidade Federal de Sergipe.

Morrison G.W. (1980). Characteristics and tectonic setting of the shoshonite rock associations. Lithos, 13:97-108.

Moura Neto W. (2015). Caracterização Geológica e Petrográfica do Stock Várzea Nova, Domínio Macururé, Sistema Orogênico Sergipano. (Trabalho de Conclusão de Curso). São Cristóvão: Universidade Federal de Sergipe.

Oliveira A.C.S. (2014). Petrogênese do Stock Granítico Monte Alegre, nordeste do Domínio Macururé, Faixa Sergipana. (Dissertação de Mestrado, Pós-Graduação em Geociências e Análise de Bacias). São Cristóvão: Universidade Federal de Sergipe.

Oliveira E.P., Toteu S.F., Araújo M.N.C., Carvalho M.J., Nascimento R.S., Bueno J.F., McNaughton N., Basilici G. (2006). Geologic correlation between the Neoprotreozoic Sergipano belt (NE Brazil) and the Yaoundé belt (Camaroon, Africa). Journal of African Earth Sciences, 44:470-478

Oliveira E.P., Windley B.F., Araújo M.N.C. (2010). The Neoproterozoic Sergipano orogenic belt, NE Brazil: a complete plate tectonic cycle in western Gondwana. Precambrian Research, 181:64-84.

Oliveira E.P., Bueno J.F., McNaughton N.J., Silva Filho A.F., Nascimento R.S., Donatti-Filho J.P. (2015). Age, composition, and source of continental arc- and syn-collision granites of the Neoproterozoic Sergipano Belt, Southern Borborema Province, Brazil. Journal of South American Earth Sciences, 58:257-280

Pearce J.A. (1982). Trace element characteristics of lavas form destructive plate margins. In: Thorpe, R. S. (Ed.). Andesites. Ney York: John Wiley. p. 525-548.

Peccerillo A., Taylor S.R. (1976). Geochemistry of Eocene calcalkaline volcanic rocks from the Kastamanu area, northern Turkey. Contributions to Mineralogy and Petrology, 58:63-81.
Rudowski L. (1989). Pétrologie et géochimie des granites transamazoniens de Campo Formoso et Carnaiba (Bahia, Brésil), et des phlogopites à émeraudes associées. (PhD Thesis). Paris: Université Pierre et Marie Curie - Paris VI.

Santos I.S. (2014). Stock Granítico Propriá, Faixa Sergipana (NE Brasil): Petrografia e Geoquímica. (Trabalho de Conclusão de Curso). São Cristóvão: Universidade Federal de Sergipe.

Santos R.A., Menezes Filho N.R., Souza J.D. (Orgs.) (1988). Programa Levantamentos Geológicos Básicos do Brasil: carta geológica, carta metalogenética/previsional - (Folha SC.24-Z-A-III Carira). Estados de Sergipe e Bahia: DNPM/CPRM. $124 \mathrm{p}$

Santos R.A., Souza J.D., Martins A.A.M., Neves J.P., Leal R.A. (1997). Mapa Geológico do Estado de Sergipe. Brasília: CPRM/DIEDIG/DEPAT, CODISE, Escala 1:250.000.

Santos R.A., Martins A.A.M., Neves J.P., Leal R.A. (1998). Programa Levantamentos Geológicos Básicos do Brasil: Geologia e recursos minerais do Estado de Sergipe. Texto explicativo do Mapa geológico do Estado de Sergipe, Brasília: CPRM/DIEDIG/DEPAT, CODISE. 156 p.

Silva C.C. (2014). Petrologia e Geocronologia do Stock Granodiorítico Lagoa do Roçado, Domínio Macururé, Faixa Sergipana-SE. (Dissertação de Mestrado, Pós-Graduação em Geociências e Análise de Bacias. São Cristóvão: Universidade Federal de Sergipe.

Silva Filho M.A., Santana A.C., Silva B.C.E., Andrade Filho E.L., Souza G.T.M., Figueroa I., Bonfim L.F.C., Braz Filho P.A., Santos R.A., Azevedo R.R., Leal R.A. (1979). Geologia da Geossinclinal Sergipana e do seu embasamento Alagoas, Sergipe e Bahia - Projeto Baixo São Francisco/ Vaza-Barris. Salvador: DNPM, Seção Geologia Básica, 13. 131 p.

Silva Filho A.F., Guimarães I.P., Brito M.F.L., Pimentel M.M. (1997). Geochemical Signatures of Main Neoproterozoic Late-Tectonic Granitoids from the Proterozoic Sergipano Fold Belt, Brazil: Significance form the Brasiliano Orogeny. International Geology Review, 39:639-659.

Silva Filho A.F., Guimarães I.P., Van Schmus W.R., Dantas E., Armstrong R., Concentino L., Lima D. (2013). Long-lived Neoproterozoic high-K magmatism in the Pernambuco-Alagoas Domain, Borborema Province northeast Brazil. International Geology Review, 55:1280-1299.

Streckeisen A.L. (1976). To each plutonic rock its proper name. Earth Science Reviews, 12:1-33.

Thompson R.N. (1982). Magmatism of the British Tertiary volcanic Province. Scottish Journal of Geology, 18:50-107.

Thompson R.N., Fowler M.B. (1986). Subduction-related shoshonitic and ultrapotassic magmatism: a study of Siluro-Ordovician syenites from the Scottish Caledonides. Contributions to Mineralogy and Petrology, 94:507-522.

Arquivo digital disponível on-line no site www.sbgeo.org.br 